Original Research Paper

\title{
Serological and Molecular Investigation of Cutaneous Leishmaniasis in Healthy Individuals from an American Cutaneous Leishmaniasis-Endemic Region
}

\author{
${ }^{1}$ Rejane Cristina Ribas-Silva, ${ }^{1}$ Taisa Rocha Navasconi, ${ }^{1}$ Laís de Souza Braga, ${ }^{2}$ Elen Paula Leatte, \\ ${ }^{1}$ Cissiara Maneti Skraba, ${ }^{1}$ Carolina Cela Conter, ${ }^{4}$ Sueli D. Borelli and ${ }^{3}$ Thaís G. Verzignassi Silveira \\ ${ }^{1}$ Postgraduate Program in Health Sciences, State University of Maringá, Brazil \\ ${ }^{2}$ Postgraduate Program in Bioscience and Physiopathology, State University of Maringá, Brazil \\ ${ }^{3}$ Department of Clinical Analysis and Biomedicine, State University of Maringá, Brazil \\ ${ }^{4}$ Department of Basic Health Sciences, State University of Maringá, Brazil
}

\author{
Article history \\ Received: 16-04-2015 \\ Revised: $29-04-2015$ \\ Accepted: 20-06-2015 \\ Corresponding Author: \\ Rejane Cristina Ribas-Silva \\ Postgraduate Program in Health \\ Sciences, State University of \\ Maringá \\ Email: rejane.c.ribas@gmail.com
}

\section{Introduction}

American Cutaneous Leishmaniasis (ACL) is clinically one of the most important zoonoses in Brazil, with 635,399 recorded cases between 1990 and 2013 (Brasil, 2009; Brasil, 2013). A majority of the ACL cases recorded in southern Brazil originated in the state of Paraná. Data obtained from the Health Surveillance Secretariat revealed that 13,899 disease cases were recorded in southern Brazil between 1990 and 2013, 13,188 of which were from Paraná (Brasil, 2013). Several northwestern cities in the state of Paraná have shown a high incidence of ACL; therefore, it is an endemic region for this disease (Curti et al., 2009; Monteiro et al., 2009). Leishmania braziliensis is the

\begin{abstract}
American Cutaneous Leishmaniasis (ACL) is a major, clinically relevant zoonosis in Brazil. The disease spectrum includes single, localized, cutaneous ulcers, diffuse cutaneous leishmaniasis and mucosal disease. A subclinical form of the disease has also been described in individuals living in ACL-endemic regions. The goal of this study was to employ immunological and molecular diagnostic methods to evaluate the presence of subclinical ACL in healthy individuals from an ACL-endemic region in northwestern Paraná. Antibodies IgG were detected by enzymeLinked Immunosorbent Assay (ELISA) and the positive samples were analyzed by indirect Immunofluorescence (IIF) for Leishmania braziliensis and Trypanosoma cruzi. Polymerase Chain Reaction (PCR), employing the MP3H/MP1L primers, amplified a fragment of Leishmania (Viannia) k-DNA. Of the 159 individuals analyzed, 31 presented ELISA-positive serology and 5 and 8 of these were IIF-positive for Leishmania and T. cruzi, respectively. All 159 individuals were PCRnegative. Most ELISA-positive individuals were males and the cities São Jorge do Ivaí and Doutor Camargo showed the highest prevalence of positive individuals. Our results reveal the presence of subclinical Leishmania infections in inhabitants of this region. Further investigation of this population may contribute to understanding the immune responses to ACL.
\end{abstract}

Keywords: Leishmaniasis, Subclinical Cases, ELISA, Polymerase Chain Reaction, Indirect Immunofluorescence main etiological agent of ACL in the state of Paraná (Lonardoni et al., 2006; Szargiki et al., 2009). The disease spectrum includes single, localized, cutaneous ulcers, diffuse cutaneous leishmaniasis and mucosal disease. A subclinical or asymptomatic form of this disease has also been observed in individuals living in the ACL-endemic regions (Sampaio et al., 2009; Brito et al., 2008; Arraes et al., 2008).

ACL is routinely detected in the laboratory by the direct detection of the parasite and immunological methods, such as the Montenegro Skin Test (MST) and Indirect Immunofluorescence (IIF) (Brasil, 2009). Enzyme-Linked Immunosorbent Assay (ELISA)-based methods of diagnosis are known to be highly sensitive (Yoneyama et al., 2007) and have been employed in the 
diagnosis of both clinical and subclinical cases of ACL (Arraes et al., 2008; Szargiki et al., 2009). Previous reports have also confirmed the applicability of Polymerase Chain Reaction (PCR) in the diagnosis of ACL, although it is not routinely used for this purpose (Yoneyama et al., 2007).

The aim of this study was to employ immunological and molecular diagnostic methods to evaluate the presence of subclinical ACL in healthy individuals native to an ACL-endemic region in northwestern Paraná.

\section{Material and Methods}

\section{Study Design}

A retrospective study was conducted using the epidemiological records of patients between the years 2005 and 2011, assisted by the Laboratório de Ensino e Pesquisa da Universidade Estadual de Maringá, Paraná (LEPAC/UEM), a Reference Center of the Ministry of Health for laboratory-based diagnosis of ACL. Individuals with ACL were identified from these records and grouped according to the municipality of their residence. Relatives and neighbors living within a $1 \mathrm{~km}$ radius of these patients, or individuals who frequently visited ACLendemic areas (woods and rivers), aged 18 years or above, were invited to take part in this study. Blood samples were collected from these subjects $(n=159)$ for ELISA-IgG and PCR analyses. ELISA-positive samples were subsequently analyzed for $T$. cruzi and Leishmania braziliensis antibodies by IIF.

\section{Sample Preparation and Storage}

A $10 \mathrm{~mL}$ aliquot of the blood sample was collected and split in two $5 \mathrm{~mL}$ tubes, one containing Ethylenediaminetetraaceticacid (EDTA) and one without an anti-coagulating agent. Serum and buffy coat fractions were obtained by centrifuging the blood samples at 3,000 rpm for $15 \mathrm{~min}$ and stored at $-30^{\circ} \mathrm{C}$ until further use.

\section{ELISA}

Promastigote forms of L. braziliensis (MHOM/BR/1987/M11272) were cultured at $25^{\circ} \mathrm{C}$ in 199 medium (Invitrogen, Carlsbad, CA, USA) supplemented with $10 \%(\mathrm{v} / \mathrm{v})$ inactivated bovine fetal serum, penicillin $\mathrm{G}\left(100 \mathrm{UI} \mathrm{mL}^{-1}\right)$, streptomycin (100 $\mu \mathrm{g} / \mathrm{mL})$ and $1 \%(\mathrm{v} / \mathrm{v})$ human urine. Parasites were washed in phosphate buffered saline (PBS; $\mathrm{pH} 7.2$ ), centrifuged at $4^{\circ} \mathrm{C}$ and $1,700 \times g$ for $10 \mathrm{~min}$, lyophilized and stored at $4^{\circ} \mathrm{C}$. The antigens were prepared according to the protocol described by Yoneyama et al. (2007). Briefly, the plates were sensitized with a dilution of the extract in carbonate-bicarbonate buffer (0.1 M, pH 9.6); the serum samples were diluted to a rate of $1: 150$ and added to this plate. The detection reaction employed an anti-human IgG-peroxidase conjugate (Sigma-Aldrich, St. Louis, MO, USA) and O-Phenylenediamine Dihydrochloride (OPD; Sigma-Aldrich). The reaction was stopped with $3 \mathrm{M} \mathrm{H}_{2} \mathrm{SO}_{4}$ and the absorbance measured at $492 \mathrm{~nm}$ using a microplate reader (Reader ASYS Microplates v.1.4;

Biochrom, Cambridge, Austria). All samples were analyzed in duplicate. Samples with an average absorbance greater than 0.68 were considered to be positive (Yoneyama et al., 2007). The assay reactivity was confirmed by against the positive and negative controls provided in each plate.

\section{DNA Extraction}

The obtained buffy coat samples were washed with phosphate buffered saline (10 mM sodium PBS, 0.15 M $\mathrm{NaCl}, \mathrm{pH}$ 7.2) and centrifuged at $3,500 \times \mathrm{g}$ for $15 \mathrm{~min}$. DNA was extracted by the guanidine-phenol method (Venazzi et al., 2007), resuspended in $50 \mu \mathrm{L}$ TE buffer (10 mM Tris, $1 \mathrm{mM}$ EDTA; $\mathrm{pH} 8.0$ ) and stored at $4^{\circ} \mathrm{C}$ until further use. One positive control $\left(10^{4} \mathrm{~L}\right.$. (V.) braziliensis promastigotes in normal human blood) and one negative control (normal human blood) was included for each group of samples extracted.

\section{Polymerase Chain Reaction}

The primers $M P 3 H\left(5^{\prime}\right.$-GAA CGG GGT TTC TGT ATG C-3') and MP1L (5'-TAC TCC CCG ACA TGC CTC TG-3') (Lopez et al., 1993) were used to amplify a $70 \mathrm{bp}$ fragment of the minicircle kinetoplast (kDNA) of subgender Leishmania (Viannia). The samples were amplified and subsequently subjected to agarose gel electrophoresis according to the protocol provided by Nietzke-Abreu et al. (2013). The reaction mixture (25 $\mu \mathrm{L}$ ) contained $1 \mu \mathrm{M}$ of each primer (Invitrogen), $1.5 \mathrm{mM}$ $\mathrm{MgCl}_{2}, 1 \mathrm{X}$ enzyme buffer, $0.2 \mathrm{mM}$ dNTP (Invitrogen), 1 $\mathrm{U}$ Taq DNA polymerase (Invitrogen) and $2 \mu \mathrm{L}$ of the sample DNA. Amplification was performed in a thermocycler (Biometra, Gottingen, Germany). The PCR conditions for primers $M P 3 H / M P 1 L$ were set as follows: an initial denaturation at $95^{\circ} \mathrm{C}$ for $5 \mathrm{~min}$, followed by 35 cycles of denaturation $\left(95^{\circ} \mathrm{C} ; 1.5\right.$ min), annealing $\left(55^{\circ} \mathrm{C} ; 1.5 \mathrm{~min}\right)$ and extension $\left(72^{\circ} \mathrm{C}\right.$; $2 \mathrm{~min}$ ) and a final extension at $72^{\circ} \mathrm{C}$ for $10 \mathrm{~min}$. The reaction products were stored at $4^{\circ} \mathrm{C}$ until further analyses. Ten microliters of the amplification products were analyzed by electrophoresis, on a $3 \%$ agarose gel stained with $0.1 \mu \mathrm{g} \mathrm{mL} \mathrm{mL}^{-1}$ ethidium bromide, at a voltage of $10-15 \mathrm{~V} / \mathrm{cm}$. A positive control (1 pg $L$. braziliensis DNA) and a negative control (water) was added to each group of samples. DNA bands were visualized using a UV transilluminator (Macro Vue UV-20; Hoefer Inc., Holliston, MA, USA). 


\section{Indirect Immunofluorescence}

Promastigote forms of L. braziliensis (MHOM/BR/1987/M11272) and an anti-human IgGFluorescein Isothiocyanate (FITC) conjugate (BioMérieux, Craponne, France) were employed for the detection of anti-Leishmania antibodies. Serum samples were serially diluted (starting from a $1 / 20$ dilution) and titers $\geq 40$ were considered to be positive (Silveira et al., 1999). An Imunocruzi antigen (Biolab, Rio de Janeiro, Brasil) and an anti-human IgG-FITC conjugate (BioMérieux) was used in the detection of antiTrypanosoma cruzi antibodies. Serum samples were serially diluted from a starting dilution of $1 / 20$ and titers $\geq 40$ were considered to be positive (Silveira et al., 1999).

\section{Statistical Analysis}

The obtained data was introduced to a Microsoft Excel $^{\circledR} 2010$ worksheet. The Stata 9.1 ${ }^{\circledR}$ (Stata Corporation, College Station, TX, USA) program was employed for data analyses. The data was analyzed by the Chi-squared test and Student's $t$-test for independent samples, with a significance level of 5\%.

\section{Ethical Considerations}

All study participants were provided with detailed information regarding the details of the study; the patients who agreed to participate in this study were asked to sign an informed consent form. The study was approved by the Permanent Committee on Ethics in Human Research of the Maringá State University, according to the report n. 153/2009.

\section{Results}

One hundred and fifty nine patients, residing in six municipalities in northwestern Paraná, Brazil, were included in this study. Of these, 104 were male and 55 were female subjects. The patients were aged between 18 and 88 years, with an average age of $45.8 \pm 16.3$ and a median age of 46 years.

Of the 159 samples analyzed, $19.5 \%$ (31) were determined to be positive for ACL by ELISA-IgG, with an absorbance $\geq 0.68$ (Yoneyama et al., 2007). Twenty (64.5\%) and $11(35.4 \%)$ of the ELISApositive samples were obtained from males and females, respectively. There was no statistically significant correlation between the gender and ELISA positivity $(\mathrm{p}=0.973)$. The age of ELISA-positive individuals ranged between 18 and 88 years, with an average age of $46.1 \pm 15.9$ and a median age of 44 years; therefore, the age and ELISA positivity were not significantly correlated $(\mathrm{p}=0.607)$.

The cities São Jorge do Ivaí $(35.48 \% ; 11)$ and Doutor Camargo $(22.59 \%$; 7) showed the highest number of subclinical cases (Table 1). No statistically significant differences were observed between the municipalities in terms of the distribution of ELISApositive individuals $(\mathrm{p}=0.447)$.

Of the 31 ELISA-positive samples identified, 5 were discovered to be IIF-positive for Leishmania, while 8 were IIF-positive for T. cruzi. All 159 individuals were PCR-negative for Leishmania (Viannia) (Fig. 1).

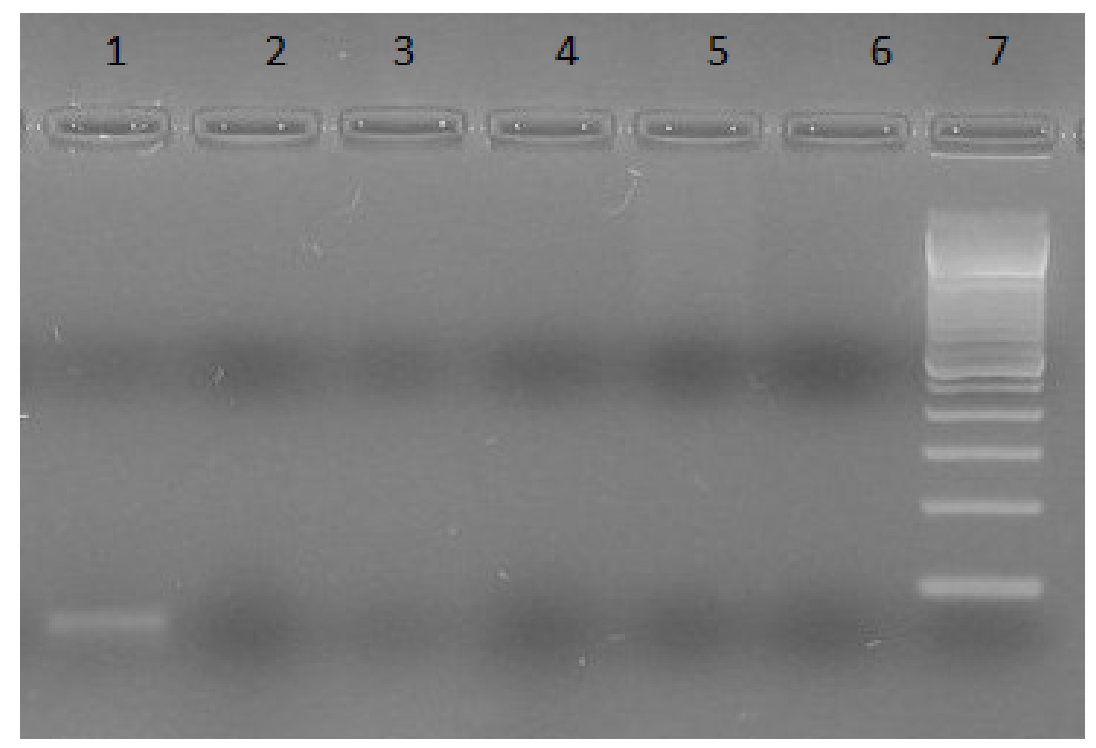

Fig. 1. Representative agarose gel showing PCR products of 70-bp (region of the minicircle kinetoplast kDNA of sub-gender Leishmania (Viannia), following amplification with MP3H and MP1L primers). Lane 1, positive control [DNA of L. (V.) braziliensis promastigote forms]; lane 2, negative control (water); lanes 3, 4, 5 and 6, DNA samples from study subjects; lane 7, MW, 100-bp molecular weight marker 
Table 1. Distribution of 31 ACL-positive individuals, as determined by ELISA, according to the municipality of residence in the northwestern region of Paraná

\begin{tabular}{lll}
\hline Municipality & Number of individuals analyzed & Number of ACL-positive individuals (\%) \\
\hline Cianorte & 22 & $2(6,45)$ \\
Doutor camargo & 29 & $7(22,59)$ \\
Jussara & 17 & $5(16,12)$ \\
Maringá & 4 & $2(6,45)$ \\
São Jorge do Ivaí & 63 & $11(35,48)$ \\
Terra Boa & 24 & $4(12,91)$ \\
Total & 159 & $31(100)$ \\
\hline
\end{tabular}

The most common clinical manifestations of ACL are single, cutaneous ulcers, which correspond to localized lesions; these may evolve to healing and mucosal disease, which mainly affects the nasal and oral cavities and whose treatment may be difficult (Brasil, 2009; Curti et al., 2009). Despite this, individuals living in endemic regions with no patent ACL-related lesions or scars may test positive for MST and serologically, suggesting a recent or subclinical infection (Nunes et al., 2006; Arraes et al., 2008; Sampaio et al., 2009). This study examined antibodies of the IgG class. Thus, it is believed that positive cases are subclinical.

A majority of the individuals evaluated in this study were males (104/159); therefore, higher disease positivity was observed in males than females; for this reason, no statistically significant difference was observed between genders, in terms of ELISA-positivity. However, previous studies have reported greater frequency of the clinical manifestations of this disease in males than females (Monteiro et al., 2009; Curti et al., 2009; Murback et al., 2011).

Our results regarding the age of the patients are not in agreement with those seen in a previous study aimed at identifying the subclinical cases of ACL in the Federal District, which reported an average incidence age of $21.16 \pm 14.01$ and a median age of 19 years. This difference arises from the inclusion of children in the previous study, contrary to this study (Sampaio et al., 2009).

The municipalities with the highest number of identified subclinical cases of were São Jorge do Ivaí and Doutor Camargo. However, no statistically significant differences were observed between the municipalities in terms of the distribution of detected subclinical cases. Previous studies have shown that ACL is endemic to the municipalities included in this study (Curti et al., 2009). Between 1986 and 2006, 412 cases of ACL were reported in Maringá, 121 in São Jorge do Ivaí and 126 in Doutor Camargo, the three municipalities with the highest prevalence of ACL in northwestern Paraná. The high ACL endemicity may explain the presence of subclinical forms of the disease in these municipalities. Previous studies have also reported the presence of subclinical cases in municipalities with high ACL endemicity (Arraes et al., 2008; Sampaio et al., 2009).
A previous study identified 11 (8.5\%) ELISApositive samples from among 130 healthy individuals living in an endemic region in Maringá city, Paraná (Arraes et al., 2008), which is in agreement with the results presented in this study $(19.5 \%)$. Some studies identified higher percentages of subclinical cases in the metropolitan area of Recife and the Federal District (67\% and 71.8\%), respectively (Brito et al., 2008; Sampaio et al., 2009), which the authors attributed to peri-domicile transmission. This is in contrast to the ACL transmission characteristics observed in northwestern Paraná, where the occurrence of ACL has been linked to proximity to woods and rivers, as well as to rural and peri-urban sections of endemic areas (Curti et al., 2009).

Several authors have described the detection of Leishmania (Viannia) DNA in peripheral blood as an appropriate tool for the diagnosis of ACL (Ferreira et al., 2006; Venazzi et al., 2007; Martins et al., 2010). However, parasite DNA was not detected in the blood of individuals analyzed in this study. An analysis of patients with a clinical history of ACL conducted by Ferreira et al. (2006) did not reveal the presence of parasite DNA; however, the results of the ELISA conducted by Ferreira et al. (2006) were in agreement with those obtained in this study. Conversely, Camera et al. (2006) successfully detected parasite DNA in samples obtained from individuals (with no prior history of ACL) living in endemic regions.

In this study, DNA was extracted from the buffy coat extracted from the patient blood samples, which may have increased the difficulty of parasite DNA detection. Parasite DNA is frequently detected in whole blood and mononuclear cell samples, rather than in buffy coat samples (Camera et al., 2006). In addition, the detection of parasites in blood samples is believed to be related to the amount of circulating parasites. Venazzi et al. (2012) identified parasite DNA solely in those patients in whom a direct examination of the lesion samples revealed a high number of amastigotes. The samples analyzed in this study originated from subclinical patients, who are likely to have low parasitemias, or may even show parasite clearance, rendering the detection of parasite DNA impossible. 
The association of different serological tests is needed to increase the positivity of LTA in the laboratory diagnostics (Yoneyama et al., 2007; Silveira et al., 1999). Thus, IIF-Leishmania was performed to compare the positivity of the ELISA-positive samples. The results of IIF were not in agreement with those obtained by ELISA, which may be a consequence of the higher sensitivity of the latter (Szargiki et al., 2009). Some studies have shown that IIF-negative samples could test positive for ACL in ELISA (Ferreira et al., 2006), including the subclinical cases (Arraes et al., 2008). Thus, the use of different antigens in sensitive techniques, such as ELISA, can provide more specific diagnosis.

In the routine, the IIF reaction is the most used for the diagnosis of ACL, but there are possibilities of crossreactions, especially with Chagas disease, so, it was performed the IFI-T. cruzi. The number of individuals determined to be IIF-positive for $T$. cruzi was higher than those that were IIF-positive for Leishmania. However, all T. cruzi IIF-positive samples presented high absorbance values in the ELISA-Leishmania assay.

A major limitation of this study was the time span between ELISA and IIF, with the latter having been performed after the former. Although the samples were storage in ideal storage conditions $\left(-30^{\circ} \mathrm{C}\right)$, antibody titers are known to decrease with time, which may lead to a higher number of negative results (Souza et al., 2012).

\section{Conclusion}

This study demonstrates the occurrence of subclinical infections in the inhabitants of northwestern Paraná. Based on the complexity of the immunological events that take place throughout the clinical development of ACL, further immune-genetic studies of subclinical cases may help elucidate why some individuals present clinical manifestations of the disease, while others remain resistant to ACL.

\section{Acknowledgment}

I would like to humbly thanks to the people who have participated in this study.

\section{Funding Information}

The authors have no support or funding to report.

\section{Author's Contributions}

RSRC: Sample collection, laboratory tests, manuscript preparation; TRN: Laboratory tests, manuscript preparation; LSB: laboratory tests; EPL: Laboratory tests; CMS: Laboratory tests; CCC: laboratory tests; SDB: manuscript preparation and revision; TGV: Laboratory tests, manuscript preparation and revision.
All authors have read and approved the submitted version of the manuscript.

\section{Competing Interest}

The authors have no conflicts of interest to declare.

\section{References}

Arraes, S.M.A.A., M.T. Marini, D. Martello, T.G.V. Silveira and M.V.C. Lonardoni et al., 2008. Investigação sorológica de casos subclínicos de leishmaniose tegumentar após um surto em uma localidade endêmica. Rev. Soc. Bras. Med. Trop., 41: 205-208. DOI: 10.1590/S0037-86822008000200016

Brasil, 2009. Ministério da Saúde. Secretaria de Atenção à Saúde. Departamento de Atenção Básica. Manual de vigilância em saúde: Zoonoses. Distrito Federal, Brasília.

Brasil, 2013. Ministério da Saúde. Secretaria de vigilância em saúde. Casos de leishmaniose tegumentar americana. Brasil, grandes regiões e unidades federadas.

Brito, M.E.F., C.J. Silva, C.M. Silva, P.R. Salazar and J.S. Coutinho et al., 2008. Clinical epidemiological profile of American tegumentary leishmaniasis at the pinto sugar mill in moreno municipality, greater metropolitan recife, pernambuco state, Brazil. Cad. Saúde Pública, 24: 2445-2448. PMID: 18949246

Camera, P.O., J. Junger, F.E.S.S. Pires, M. Mattos and M.P. Oliveira-Neto et al., 2006. Haematogenous dissemination of Leishmania (Viannia) braziliensis in human American tegumentary leishmaniasis. Trans. R. Soc. Trop. Med. Hyg., 100: 1112-1117. DOI: $10.1016 /$ j.trstmh.2006.02.014

Curti, M.C.M., T.G.V. Silveira, S.M.A.A. Arraes, D.A. Bertolini and P.D. Zanzarini et al., 2009. Aspectos epidemiológicos da Leishmaniose Tegumentar Americana na região Noroeste do Estado do Paraná. Rev. Ciênc. Farm. Básica, 30: 63-68.

Ferreira, M.P., A.M. Roselino, M.M. Nascimento, J.M. Aires and J.F. Figueiredo, 2006. Sensitivity of an immunoenzymatic test for detection of anti- $L$. brasiliensis antibodies compared to other tests used for the diagnosis of American cutaneous leishmaniasis. Rev. Inst. Med. Trop. Sao Paulo, 48: 215-217. DOI: 10.1590/S0036-46652006000400008

Lonardoni, M.V.C., T.C.G. Silveira, W.A.A. Alves, A.N.S.M. Elkhoury and U.A. Membrive et al., 2006. Human and canine American cutaneous leishmaniasis in Mariluz, Paraná State, Brazil. Cad. Saúde Pública, 22: 2713-2716. PMID: 17096049

Lopez, M., R. Inga, M. Cangalaya, J. Echevarria and A. Llanos-Cuentas et al., 1993. Diagnosis of Leishmania using the polymerase chain reaction: A simplified procedure for field work. Am. J. Trop. Med. Hyg., 49: 348-356. PMID: 8396860 
Martins, L., A. Alexandrino and G. Guimaraes, 2010. Detection of Leishmania braziliensis DNA in American tegumentary leishmaniasis patients. Rev. Saude Publica, 44: 571-574. PMID: 20428600

Monteiro, W.M., H.C.A. Neitzke, M.E.E.C. Ferreira, G.C. Melo and M.G.V. Barbosa et al., 2009. Population mobility and production of American tegumentary leishmaniasis in the State of Paraná, southern Brazil. Rev. Soc. Bras. Med. Trop., 42: 509-514. PMID: 19967232

Murback, N.D.N., G.H. Filho, R.A.F. Nascimento, K.R.O. Nakazoto and E.M.C. Dorval, 2011. Leshmaniose tegumentar americana: estudo clínico, epidemiológico e laboratorial realizado no Hospital Universitário de Campo Grande, Mato Grosso do Sul, Brasil. An. Bras. Dermatol., 86: 55-63. PMID: 21437523

Nietzke-Abreu, H.C., M.S. Venazzi, M.V.Z. Bernal, K.R. Reinhold-Castro and F. Vagetti et al., 2013. Detection of DNA from Leishmania (Viannia): Accuracy of polymerase chain reaction for the diagnosis of cutaneous leishmaniasis. Plos One, 8: e62473. DOI: 10.1371/journal.pone.0062473.

Nunes, A.G., E.V. Paula, R. Teodoro, A. Prata and M.L. Silva-Vergara, 2006. Epidemiological aspects of American tegumentary leishmaniasis in Varzelândia, Minas Gerais, Brazil. Cad. Saúde Pública, 6: 1343-1347. PMID: 16751973

Sampaio, R.N.R., M.C. Gonçalves, V.A. Leite. B.V. França and G. Santos et al., 2009. Study on the transmission of American cutaneous leishmaniasis in the Federal District. Rev. Soc. Bras. Med. Trop., 40: 686-690. PMID: 20209356
Silveira, T.G., S.M. Arraes, D.A. Bertolini, U. Teodoro and M.V. Lonardoni et al., 1999. The laboratory diagnosis and epidemiology of cutaneous leishmaniasis in Paraná State, southern Brazil. Rev. Soc. Bras. Med. Trop., 32: 413-423. PMID: 10495672

Souza, A.P.A., J.A. López, D.L.M. Moura and F.W. Mendonça-Lima, 2012. Influência de diferentes condições de armazenamento sob congelamento na reatividade de anticorpos séricos. Rev. Bras. Anal. Clin., 44: 39-43.

Szargiki, R., E.A. Castro, E. Luz, W. Kowalthuk and A.M. Machado et al., 2009. Comparison of serological and parasitological methods for cutaneous leishmaniasis diagnosis in the state of Paraná, Brazil. Braz. J. Infect. Dis., 13: 47-52. DOI: $10.1590 /$ S1413-86702009000100011

Venazzi, E.A.S., A.C.B.S. Roberto, I.P. Barbosa-Tessmann, P.D. Zanzarini and M.V.C. Lonardoni et al., 2007. Detection of Leishmania (Viannia) DNA in blood from patients with American cutaneous leishmaniasis. Exp Parasitol., 115: 399-402. DOI: 10.1016/j.exppara.2006.10.002

Yoneyama, K.A.G., L.D. Peder, M.V.C. Lonardoni and T.G.V. Silveira, 2007. Diagnosis of American cutaneous leishmaniasis by enzyme immunoassay in patients from Northern Paraná State Brazil. Braz. J. Infect. Dis., 11: 360-364. PMID: 17684640 